\title{
ABBREVIATIONS USED IN THE FOOTNOTES
}

APP Historische Reichskommission, Die Auswärtige Politik Preussens, 1858-1871 (Vols. I-vI, VIII-x, Berlin, 1932-1939)

DPO Heinrich Ritter von Srbik, ed., Quellen zur deutschen Politik Österreichs, 1859-1866 (five vols., Oldenburg, 1934-1938)

$G W$ Herman von Petersdorff and others, eds., Bismarck: Die gesammelten Werke (fifteen volumes, Berlin, 1923-1933)

$H W$ Julius Heyderhoff and Paul Wentzcke, eds., Deutscher Liberalismus im Zeitalter Bismarcks, Eine politische Briefsammlung (two vols., Bonn, 19251927)

$O D$ Ministère des Affaires Étrangères, Les origines diplomatiques de la guerre de 1870/71, Recueil de documents officiels (29 vols., Paris, 1910-1932)

RKN Hermann Oncken, ed., Die Rheinpolitik Kaiser Napoleons III. von 1863 bis $18 \% 0$ und der Ursprung des Krieges von 1870/71 (three vols., Berlin, 1926)

SBHA Stenographische Berichte über die Verhandlungen des Landtages, Haus der Abgeordneten

SBHH Stenographische Berichte über die Verhandlungen des Landtages, Herrenhaus

SBR Stenographische Berichte über die Verhandlungen des Reichstags des Norddeutschen Bundes 
